\title{
Leiomyosarcoma of the cervix uteri
}

INSERM

\section{Source}

INSERM. (1999). Orphanet: an online rare disease and orphan drug data base.

Leiomyosarcoma of the cervix uteri. ORPHA:213807

Leiomyosarcoma of the cervix uteri is a rare, malignant mesenchymal tumor of smooth muscle origin, macroscopically appearing as a large, poorly circumscribed mass, often protruding from the cervical canal or expanding it circumferentially. The most common presenting symptoms are vaginal discharge or bleeding, pain in the lower abdomen and a bulky cervical mass. There is a reported tendency to metastatsize hematogenously, especially to the lungs, peritoneum, bones and the liver. 